\title{
The familial occurrence of berry aneurysm
}

\author{
P. J. V. BEUMONT
}

From the Maudsley Hospital, Denmark Hill, London

In 1954 Chambers, Harper, and Simpson wrote 'that there may be a familial factor in the occurrence of intracerebral aneurysm is a possibility that has not been advanced, to the knowledge of the authors'. However, O'Brien in 1942 had reported a case of middle cerebral aneurysm in a man whose twin brother had died eight years previously under conditions strongly suggestive of subarachnoid haemorrhage. A similar pair of identical twins was described by Jokl and Wolffe (1954). Since 1954 several reports of intracranial aneurysm in more than one member of a family have been published.

The purpose of this paper is to present a family in which three members have had congenital intracranial vascular lesions. The case histories and relevant radiological findings of three sisters will be given. In two of these cases rupture of an intracranial aneurysm occurred at approximately the same time in life. In the third case, considerably younger, an angioma with an associated aneurysm was discovered incidentally during the course of a psychiatric illness. Reference will be made to those instances of intracranial aneurysm occurring in more than one member of a family that have been cited in the English language literature.

\section{CASE HISTORIES}

CASE 1 Mrs. M. M., a 45-year-old woman, was transferred from an acute psychiatric unit to the Maudsley Hospital on 3 January 1966 for investigation and treatment of a depressive illness and hypothyroidism. Her family tree is shown in Figure 1. Her father had died aged 75 , following a 'stroke'. Her mother, who had a rheumatic heart condition, died at the age of 67 of pneumonia. The patient was the sixth of eight siblings. The eldest brother died of lung carcinoma in 1965, aged 60. An elder sister had recovered from a subarachnoid haemorrhage (see Case 2). A second sister was admitted to hospital for investigation during January 1967 (see Case 3). Two further older sisters were healthy. A younger sister died aged 19 of 'nephritis'. A younger brother, a diabetic, had several psychiatric referrals and eventually killed himself when he was 35 (1960). The patient has two children-a boy aged 23 and a girl aged 18. Both are healthy. She smoked 40 cigarettes a day and drank alcohol moderately. After the death of her brother in 1960 she had felt depressed for several months but had not sought psychiatric treatment.
In 1963 she had been accused in a robbery case. The charges were subsequently withdrawn. Nevertheless, the case received much unfavourable publicity and she became depressed, anxious, and irritable. In December 1965 she complained of headaches that had been present for the previous six months. They were usually on the right side of her head and lasted for several days at a time. In May 1966 she was seen at a neurological outpatient department where the headaches were considered to be 'predominantly depressive in nature'. Treatment with imipramine was initiated. Her headaches and depression persisted, and in December 1966 she was admitted to St. Francis Hospital from where she was transferred to the Maudsley.

On admission she reported a weight gain of 3 st. over the previous four years. Her menses had remained normal. She appeared depressed and self-reproachful. Her hair was coarse and her eyelids puffy. Blood pressure was $110 / 70 \mathrm{~mm} \mathrm{Hg}$ and pulse $60 / \mathrm{min}$, sinus rhythm. There was a moderate bilateral proptosis with bilateral lid-lag. There was a soft bruit over the right eye, synchronous with the pulse and possible papilloedema in the right eye; the visual fields were normal. She commented on a throbbing noise in both ears which was lessened by pressure over the carotid arteries. There was a mild microcytic anaemia. Electrolytes, serum cholesterol, urinary corticosteroids, and PBI were within the normal range. A glucose tolerance test was normal. Tests for thyroid auto-antibodies were compatible with hypothyroidism. Radioactive iodine uptake by the thyroid was $10 \%$ of the dose administered after 24 hours. Following TSH it rose only to $14 \%$. Electrocardiogram was abnormal with flat $\mathrm{T}$ waves on the standard leads and V 4-7; EEG showed no definite abnormality.

Radiographs of the skull revealed a very deep pituitary fossa, with thin dorsum sellae and posterior clinoid

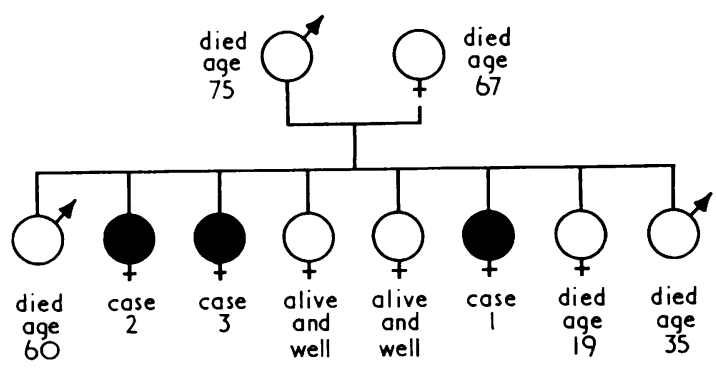

FIG. 1. The family tree. The black circles indicate members known to have intracerebral aneurysm. 
processes. The optic foramina appeared normal. An air encephalogram showed minimal displacement to the right with a depression of the roof of the body and anterior part of the trigone of the left lateral ventricle. The cistern of the corpus callosum was depressed. These appearances suggested a left parietal tumour. A carotid angiogram (Fig. 2) revealed a left parietal angioma supplied by the middle and anterior cerebral arteries, and drained by one large and several small cortical veins. There was also an aneurysm of the left carotid syphon.

In view of the hypothyroidism, the patient was treated with thyroxine. Her depressive symptoms improved, and she was discharged in March 1967. A follow-up radiograph of the skull and visual fields on 25 August 1967 showed no change from the previous findings.

She was well when last seen at follow-up in February 1968.

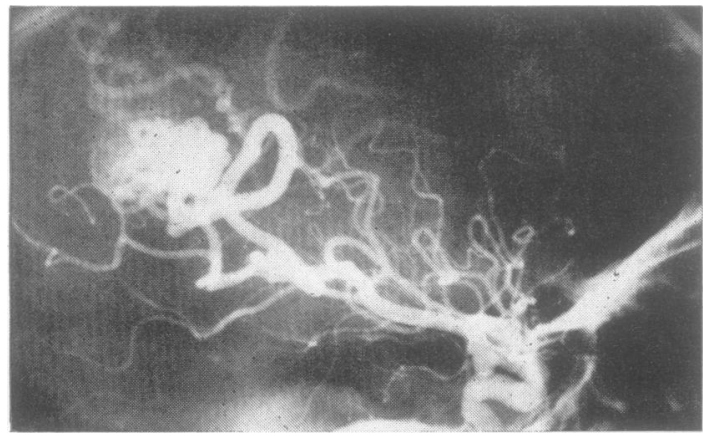

FIG. 2. Left carotid angiogram from Case 1. There is an angioma in the parietal region and also an aneurysm of the carotid syphon.

CASE 2 Mrs. K. D., aged 56, the sister of Case 1, was transferred from her local hospital to the Brook General Hospital on 21 January 1963. She had no children and had had no previous illnesses of note.

On 17 January 1963 she had been found unconscious on the floor by her cleaner. There was a bruise in the occipital region. She could not recognize her husband and mumbled incoherently. She was admitted conscious but confused to the local general hospital. She was noted to have slight neck stiffness and equivocal plantar responses. Lumber puncture performed three hours after the onset revealed a heavily bloodstained cerebrospinal fluid with marked xanthochromia of the supernatant fluid. On 20 January, she developed bilateral sixth nerve palsies and diplopia, and was subsequently transferred to the Brook General Hospital. On the following morning she was noted to have slight dysphasia. Blood pressure was 160/95. A bilateral carotid angiogram demonstrated a moderately large aneurysm on the trifurcation of the middle cerebra artery on each side (Figs. 3 and 4). There was spasm affecting both carotid trees, but no evidence of shift. The mild speech defect was judged to be evidence that the aneurysm on the left side had bled. Craniotomy was suggested but the patient refused her consent. On 23

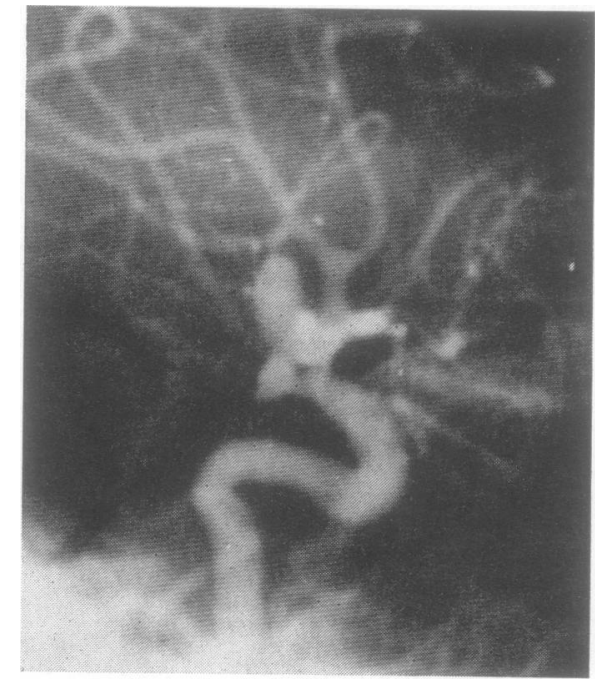

FIG. 3. Left carotid angiogram from Case 2. There is an aneurysm at the trifurcation of the left middle cerebral artery.

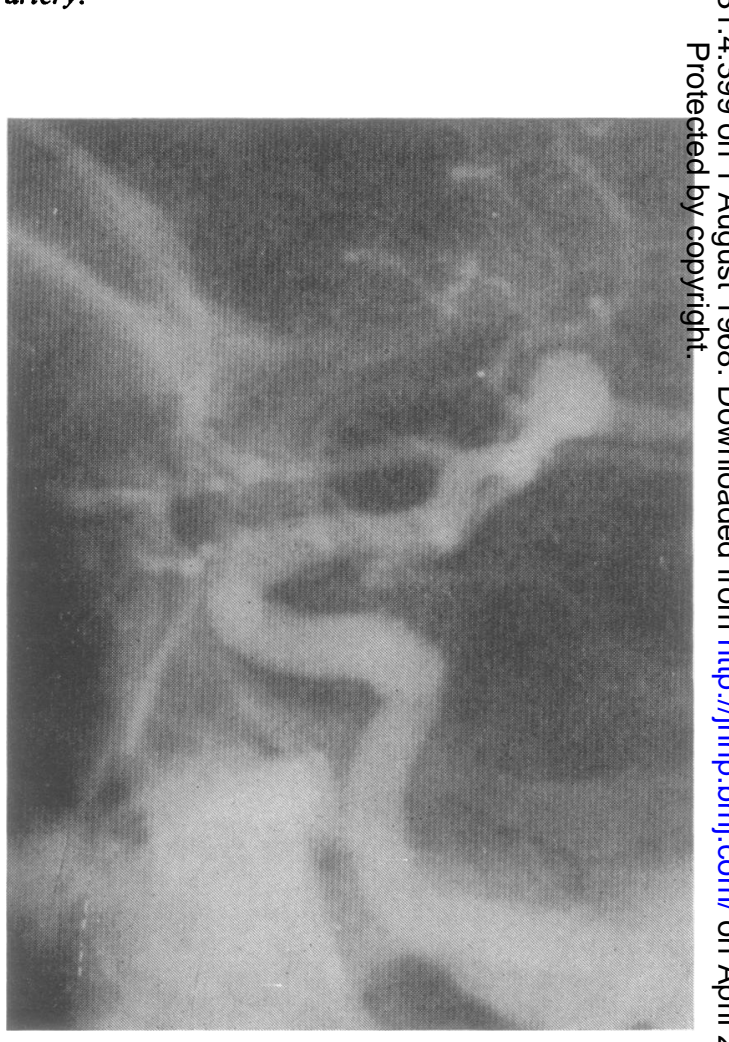

FIG. 4. Right carotid angiogram from Case 3. There is an 0 aneurysm at the trifurcation of the right middle cerebral $N$ artery. 
January the patient had one generalized convulsion. However by 14 February 1963 all abnormal signs had resolved. A check left carotid angiogram showed that the spasm had disappeared, but the aneurysm was still of the same size. The patient was discharged shortly thereafter and was well in February 1968.

CASE 3 Mrs. L. B., aged 58, another sister of Case 1 and herself the mother of three children, had had no previous relevant illnesses. She was admitted to the Atkinson Morley Hospital on 8 January 1967 with a short history of severe shooting pains in the occipital region. She was conscious but unable to tell the day or date. Memory appeared normal. There was slight dysarthria. She had vomited on several occasions. Her neck was noted to be stiff and the left carotid artery in the neck felt weaker on palpation than did the right. There was a left facial paresis and the tongue and palate deviated to the left. The limbs on the left side were weak and their coordination impaired. Pulse was $76 / \mathrm{min}$ and blood pressure $140 / 80$. CSF pressure was $210 \mathrm{~mm}$, and protein content $800 \mathrm{mg} / 100 \mathrm{ml}$. There was no xanthochromia.

The patient was treated conservatively until 18 January, when she developed papilloedema. On 21 January a bilateral carotid angiogram showed an irregular bilocular posteriorly pointing right posterior communicating artery aneurysm (Fig. 5). There was marked narrowing of the supra-clinoid portion of the internal carotid artery, and of the adjacent proximal portions of the anterior and middle cerebral arteries due to spasm. A slight straightening of the supra-clinoid portion of the internal carotid artery with elevation of the middle cerebral artery was considered to be due to a small local haematoma. There was good cross-flow from left to right.

On 26 January 1967, craniotomy was performed and the aneurysm was exposed lying posterior to the carotid artery in the most medial part of the right Sylvian fissure. It was partly adherent to the medial aspect of the

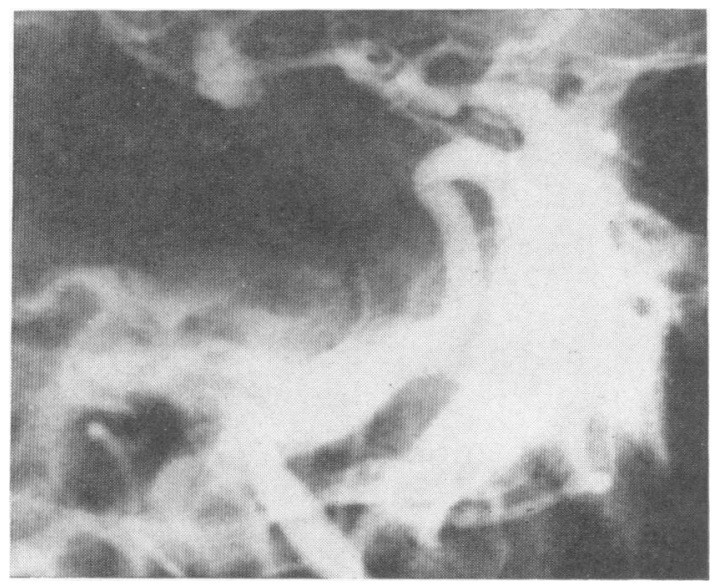

FIG. 5. Right carotid angiogram from Case 3. There is an aneurysm on the right posterior communicating artery. Note also the arterial spasm. temporal lobe. Further dissection exposed a large posterior communicating artery. The exact relationship was that the aneurysm arose from the posterior aspect of the right carotid by a broad neck and was adherent to the posterior communicating artery which ran above it. It was impossible to clip across the neck of the aneurysm without including the posterior communicating artery. Therefore the aneurysm was partially wrapped with muslin. The right carotid angiogram was repeated on 31 January. It showed the aneurysm unchanged in size. Ligation of the carotid artery in the neck was performed on February 1967. There were no immediate postoperative ill effects, but recovery was complicated by anaemia and a right basal pneumonia. The patient's condition improved thereafter and she had remained well until February 1968.

\section{DISCUSSION}

Reports in the English literature of more than one case of intracerebral aneurysm in a family are given in Table I. Published references in the foreign literature are equally rare. Becker (1966) cites the following: Asenjo et al. (1957); Gowers and Greenfield (according to Tonnis, 1948); Eck (1957); and Erbslöh (1960). Except for these isolated instances, there is little direct evidence that a familial factor is of importance in the pathogenesis of intracranial aneurysm. Walton (1956) offered no proof for this assertion. Sahs, Peiret, Locksley, Nishioka, and Skultety (1966) referred to instances of familial occurrence in the literature, but the matter is not further dealt with in the Report of the Co-operative Study. The only prospective approach was that of Koch (1957) who reported a man of 41 dying following rupture of a cerebral aneurysm whose twin brother was alive and well 14 months later.

The present paper is, to our knowledge the first in which a fairly full family history including apparently unaffected siblings has been reported. Superficially, the pattern appears to be that of a simple dominant inheritance. It has often been suggested that the congenital factor in Berry aneurysms is a defect in the arterial wall. It is suggested that this defect may be inherited and that the subsequent development of the aneurysm, and even its eventual rupture, may be considered as variations in penetrance.

\section{SUMMARY}

Three cases of cerebral aneurysm are described in one family. The family incidence of cerebral aneurysm is discussed.

The author would like to thank Mr. J. R. Gibbs, Mr. L. S. Walsh, and Dr. G. F. M. Russell for permission to 
TABLE I

REPORTS OF THE FAMILIAL OCCURRENCE OF CEREBRAL ANEURYSM IN THE ENGLISH LANGUAGE LITERATURE ${ }^{1}$

Author

Relationship

Case 1 (Sex, age, site)

Case 2 (Sex, age, site)

O'Brien (1942)

Chambers et al. (1954)

Walton (1956)

Ross (1959)

Ullrich and

Sugar (1960)

Stark (1962)

Phillips (1963)

Identical twins

Father and son

Sibs, mother and daughter

Mother and daughter

Brothers

Brothers

Brothers

M. aged 34. Origin of left m.c.a.

M. aged 52. Left m.c.a.

No details given

F. aged 64. Origin of p.com.a.

M. aged 50. Left m.c.a.

M. aged 45. Left m.c.a.

M. aged 45. Site unknown

Son of Case 1 preced- $\quad$ M. aged 28. Left a.c.a.

$\int$ ing

Sisters (3)

Sisters

M. aged 32. Left int.car.a.

No details given

F. aged 33. Right post com.a.

Matson (addendum to Phillips' paper)

Son, his father, and his sister

Sibs

Chakravorty and

Gleadhill (1966)

Pratt (1967)
Mother and son

Mother and son

2 instances of

$\int$ parent and child
M. aged 26. Right int.car.a.

M. aged 52. Multiple aneurysms

F. aged 62. Right car. sinus

F. aged 42. Left m.c.a.

No details given
M. aged 26. Site unknown

M. aged 21. A.com.a.

F. aged 32. Left m.c.a.

M. aged ? A.com.a.

M. aged 49. Right m.c.a. (identica

position on opposite side)

M. aged ? Multiple aneurysm intraextracranial

F. aged ? Right int.car.a.

F. aged 37. Right post com.a. (identical site)

Father: details not known

Sister: details not known

F. aged 45. Left m.c.a.

M. aged 34. Left car. bifurcation

M. aged 15. A.c.a.

${ }^{1}$ The relationship, sex and age of affected persons together with site of aneurysm are given where available. Key to abbreviations: $\mathrm{M}$. = Male. F. = Female. m.c.a. = Middle cerebral artery. a.c.a. = Anterior cerebral artery. a.com.a. $=$ Anterior communicating artery. p.com.a. $=$ Pos $=$ terior communicating artery. int.car.a. = Interior carotid artery.

publish details of cases; Dr. J. Ambrose for permission to publish radiographs; Dr. Eliot Slater and Mr. J. J. McCabe for their criticism; and especially Dr. R. D. Hoare for his advice and encouragement.

\section{REFERENCES}

Becker, P. E. (1966). Humangenetik, Vol. 5 Pt I. (Krankheiten des Nervensystems). Thieme, Stuttgart.

Chakravorty, B. G., and Gleadhill, C. A. (1966). Familial incidence of cerebral aneurysms. Brit. med.J., 1, 147-148.

Chambers, W. R., Harper, B. F., and Simpson, J. R. (1954) Familial incidence of congenital aneurysm of cerebral arteries. Report of cases of ruptured aneurysm in father and son. $J$. Amer. Med. Ass., 155, 358-359.

Jokl, E., and Wolffe, J. B. (1954). Sudden non-traumatic death associated with physical exertion in identical twins. Acto Genet. Med. (Roma), 3, 245-246.
Koch, G. (1957). Ergebuisse aus der Nachuntersuchung der Berliêㄹ Zwilbingsserve nach 20-25 Jahren (Vorläufige Ergebuiss. Acta genet. (Basel), 7, 47-52,

O'Brien, J. G. (1942). Subarachnoid haemorrhage in identical twi(ึ). 옥 Brit. med.J., 1, 607-609.

Phillips, R. L. (1963). Familial cerebral aneurysm. J. Neurosukg., 20, $701-703$.

Pratt, R. T. C. (1967). The Genetics of Neurological Disorder. Oxf@e을 University Press, London.

Ross, R. T. (1959). Multiple and familial intracranial vascuratr lesions. Canad. med. Ass. J., 81, 477-479.

Sahs, A. L, Peiret, G., Locksley, H. B., Nishioka, H., and Skultety F. M. (1966). Preliminary remarks on subarachnoid haemor- $\infty$ rhage. J. Neurosurg., 24, 782-788.

Stark, D. C. (1962). Effects of giving vasopressors to patients ono monoamine-oxidase inhibitors. Lancet, 1, 1405-1406.

Ullrich, D. P., and Sugar, O. (1960). Familial cerebral aneurysms including one extracranial internal carotid aneurysm. Neurology (Minneap.), 10, 288-294.

Walton, J. N. (1956). Subarachnoid Haemorrhage, p. 350. E. and S. (D Livingstone, Edinburgh. 